\title{
A PRODUÇÃO LEGISLATIVA DA COMISSÃO DE DIREITOS HUMANOS E LEGISLAÇÃO PARTICIPATIVA (CDH) DO SENADO FEDERAL NO PERÍODO DE 2005- 2018
}

\author{
Jonatas Nogueira Aguiar de Souza e Silva ${ }^{1}$
}

Bruno de Castro Rubiatti ${ }^{2}$

\begin{abstract}
Resumo
Partindo da categorização do bicameralismo brasileiro como forte, devido alta simetria e incongruência, o presente artigo tem como foco analisar a produção legislativa da Comissão de Direitos Humanos e Legislação Participativa do Senado Federal, cobrindo desde o seu ano de criação até a última legislatura completa (2005-2018). O objetivo do trabalho é contribuir para a agenda de Estudos Legislativos que focam as Comissões, visando a importância do Senado como instância deliberativa e somar com a agenda de estudos do Senado. Foi elaborada uma base de dados a partir site do Senado, na área restrita as atividades das Comissões, foi coletado todos os pareceres da comissão. Tendo isso, é possível inferir a atuação da Comissão. Assim, é feita a discussão bibliográfica referente aos Estudos Legislativos, respaldando a necessidade de estudar o Senado, Comissões e a CDH. Vale ressaltar que, a pesquisa é de caráter exploratório devido a carência dos estudos acerca do Senado e Comissões. É visto dentro da Comissão há predominância de reuniões informacionais frente as deliberativas, crescente número de reuniões nos seus 14 anos de existência, o que demostra a sua institucionalização. Sobre os projetos que passaram pela comissão, há alta frequência de projetos legislativos, taxa significativa de projetos oriundos da Sociedade Civil e ínfima participação do Executivo. É notável a presença de vários partidos nas proposições e predominância de um partido nas relatorias. Em relação aos pareceres, percebe-se os "aprovados" e "emendas/substitutivos" com maiores frequências. Os dados refletem o que é esperado pela bibliografia. A Comissão segue o desenho feita para ter, os seus mecanismos internos a permitem se institucionalizar tanto no âmbito informacional como deliberativo. A sua função como órgão deliberativo é assegurada, devido a taxa significativa de emendas/substitutivos.
\end{abstract}

Palavras-Chave: Senado brasileiro; Comissões; Senado Federal; Comissões Legislativas

\section{INTRODUÇÃO}

Este trabalho tem por objetivo analisar a produção legislativa da Comissão de Direitos Humanos e Legislação Participativa do Senado Federal (CDH). Dentro disso, foram analisados os relatórios aos projetos votados na $\mathrm{CDH}$ desde o ano da sua criação até a última legislatura completa

\footnotetext{
1 Graduando em Ciências Sociais pela UFPA, bolsista de Iniciação Científica (PIBIC/UFPA), jonatassouza.silva99@gmail.com orcid.org/0000-0001-5281-6720.

2 Professor de Ciência Política da UFPA, Doutor em Ciência Política pela Unicamp, bcrubiatti@gmail.com orcid.org/0000-0002-3167-4804.
} 
(2005-2018). Foi escolhido esta comissão dada a importância dos direitos humanos no cenário político e social e a escolha do Senado faz jus a força do bicameralismo brasileiro nos eixos de simetria e incongruência, que o torna forte como instância deliberativa; assim como pela falta de estudos sobre o Senado brasileiro com foco nas suas comissões.

Sendo o bicameralismo brasileiro forte, uma vez que há alta simetria e incongruência ${ }^{3}$, estudar o funcionamento de ambas as casas se torna importante, uma vez que esses fatores criam Casas com preferências distintas. Os métodos de seleção para o Senado com eleições majoritárias tendem exigir experiência política, tal fato é comprovado visto que "o Senado demonstra que há uma concentração da experiência política, adquirida em diversas instituições. Se há os outsiders, ou novatos, eles são em número muito inferior àqueles socializados na política” (Lemos e Reninchesky, 2008, p.103). Além disso, "as regras para a composição do Senado brasileiro viabilizam a qualificação diferenciada dos senadores, frente aos deputados, e os incentivam a atuarem como contrapesos aos interesses da maioria nacional representada na Câmara" (Araújo, 2012, p.97). Sendo assim, "encontram-se duas casas com simétricos poderes legislativos e com diferentes atores, exigindo uma maior discussão das pautas, o que, por sua vez, poderia melhorar o conteúdo das matérias” (Souza e Silva, 2019, p.84).

Dentro desse quadro de diferenças, é visto grande esforço nos estudos sobre a Câmara dos Deputados, sendo o Senado deixado em segundo plano. Um ponto que torna maior o volume de análises sobre a Câmara dos Deputados o papel desempenhado pelo Executivo na proposição dos projetos de lei aprovados e, por esses iniciarem seu trâmite pela Câmara dos Deputados, a câmara baixa acaba por receber destaque nas análises. Junto a isso, a simetria do bicameralismo brasileiro também impacta sobre a concentração de estudos na primeira câmara: como ambas as casas possuem alta simetria, o Senado pode ter o seu tramite assemelhado a Câmara - inclusive porque são os mesmos partidos nacionais que concorrem para ambas as casas. Porém existem outros fatores que tornam distintas as análises da Câmara alta. A incongruência é um desses pontos, assim como os Regimentos Internos de ambas as casas que tem as suas distinções, outro ponto são as regras de tramite. Tais regras delimitam que todas as matérias que tiverem origens exógenas ao Legislativo devem iniciar seu tramite pela Câmara dos Deputados, sendo assim o Senado é visto como câmara revisora no sistema navette ${ }^{4}$. Porém, ambas as casas possuem poder de iniciar, aprovar e rejeitar

\footnotetext{
${ }^{3}$ Que são semelhantes ou igual poder Legislativo e métodos distintos de formação das casas respectivamente

${ }^{4} \mathrm{O}$ sistema de navette é adotado na resolução de conflito entre as casas legislativas brasileiras. Ele consiste em um projeto tramitar de uma casa para outra. Dessa forma, um projeto aprovado na câmara de origem passa para a análise da câmara revisora que pode aprovar, emendar ou rejeitar o projeto. No caso brasileiro, se o projeto for aprovado, seguirá para a sanção presidencial. Caso seja rejeitado segue para o arquivo, sem possibilidade de a câmara de origem insistir no projeto. Caso seja emendado ou apresentado substitutivo, retorna para a câmara de origem que decidirá se acata ou não as alterações (Rubiatti, 2017).
} 
matéria. Dessa forma, mesmo que com distintos números de matérias ambas as Casas possuem produção legislativa:

De toda forma, conforme a Constituição brasileira, o Senado é a casa revisora na quase totalidade das proposições que tramita em regime bicameral. Logo, a Casa tem uma única oportunidade de apreciar os projetos que recebe, a menos que sejam projetos dos próprios senadores ou propostas de emenda constitucional (Araújo, 2008, p.205).

Mesmo diante da perspectiva do Senado como câmara revisora é visto que "a pauta legislativa do Senado é ocupada em sua maior parte com projetos dos próprios parlamentares, sendo os senadores responsáveis por 72,2\% do número de propostas avaliadas no período" (Araújo, 2008, p.211). Ou seja, dentro do próprio Senado majoritariamente são avaliadas matérias de origem da própria casa, todavia isso não representa que a Casa não realize a função revisora. Em trabalho sobre o Senado como câmara revisora é visto que "a Câmara Alta retém parte considerável dos projetos por ela revisados, mas também dá continuidade à maior parte destes projetos” (Rubiatti, 2017, p.68). Ou seja, existe tanto a produção legislativa como a revisão em si no Senado, dando a casa a dupla função de iniciar e revisar legislação com peso, devido a estrutura institucional que estimula esse comportamento.

Ainda é visto, no estudo de Araújo (2008) o destino das matérias apreciadas no Senado. Estas tiveram parecer aprovado em $22,4 \%$ das propostas da própria Casa, seguida de $61,1 \%$ e $90,4 \%$ das proposições dos deputados e do Executivo respectivamente e $100 \%$ no que se refere ao judiciário ${ }^{5}$. Nisso é visto que há uma grande filtragem das matérias da própria Casa. Em outro estudo sobre a produção legislativa é visto que "se examinarmos os projetos dos deputados, $75 \%$ dos 156 casos passam pelo crivo do exame da própria Casa, porém são rejeitados definitivamente no Senado" (Ricci, 2008, p.250). Assim como “dos 200 projetos senatoriais, 166 (83\%) são rejeitadas no próprio Senado[...], isso significa que Câmara e Senado atuam diferentemente no âmbito do processo legislativo" (Ricci, 2008, p.251). Sendo dessa forma visto que o Senado atua como instância revisora com forte poder de veto. Ainda é apontado por Rubiatti (2017) que 41\% dos projetos em revisão no Senado são retidos na Casa, dentre esses aqueles iniciados pelos Deputados tem 52,7\% de retenção. Os projetos iniciados pelo Executivo têm 90,1\% de aprovação no Senado. Dessa forma encontra-se um Senado forte, com proposição, revisão e rejeição de matérias.

\footnotetext{
${ }^{5}$ Tal taxa de aprovação, segundo o autor, é decorrente de que as pautas enviadas pelo Judiciário têm caráter administrativo interno, dessa forma não haveria a necessidade de alterar tais projetos que são de competência do Judiciário. "O Executivo tem a prerrogativa sobre proposições de leis administrativas, muitas das quais também de natureza consensual - como as do Judiciário, essas são acatadas pelo Legislativo de forma igualmente ágil” (Araújo, 2008, p.215)
} 
Tendo em vista as atividades legislativas do Senado, vale lembrar os mecanismos de funcionamento que culminaram nessa organização. A centralização de poderes nos líderes partidários foi o fator fundamental no Legislativo para a efetivação da agenda tanto do Executivo como do Legislativo. Do outro lado, o Executivo foi dotado de amplos poderes de legislar. Figueiredo e Limongi (1998) são pioneiros nesta análise. Em contraposição a literatura pessimista do presidencialismo de coalizão eles demonstram como os fatores endógenos do sistema político brasileiro transformaram o sistema em governável. Dessa forma, Freitas e Vasques (2017) pontuam que

A centralização do poder decisório nos Líderes partidários e no presidente é nomeada pelos autores como a base do presidencialismo de coalizão. Portanto, a despeito dos incentivos que as regras eleitorais e partidárias possam exercer nos partidos e em seus políticos, instituições endógenas a relação entre Legislativo e Executivo promoveram uma centralização do processo decisório no Executivo e nos líderes partidários” (Freitas e Vasques, 2017, p.13)

Pontuado os poderes Legislativos, foi outorgado ao chefe do Executivo na constituinte de 1988 poderes como: as Medidas Provisórias (MP) com alteração imediata do status quo, o Poder de Veto (total e parcial) permitindo ao Executivo afirmar sua posição após o trâmite legislativo; Pedido de Urgência sobre seus, lhe permitindo acelerar o tramite das matérias originadas por ele mesmo; exclusividade em pautas administrativas e orçamentárias; disposição de cargos Ministeriais a sua escolha. Com estas prerrogativas o Executivo domina ferramentas suficientes para montar a sua coalizão e administra-la.

Tendo essa nova configuração, Santos e Almeida (2011) apontam a classificação do Legislativo brasileiro como reativo, sendo este aquele que delega as principais iniciativas ao Executivo: a agenda e prioridades transformam-se em pauta do chefe de Estado que é negociada posteriormente com os partidos da coalizão. Mesmo havendo esse quadro de preponderância do Executivo, é visto na literatura que a agenda não se configura como unilateral do Executivo, uma vez que a agenda do Executivo não é vista como agenda do partido do presidente, mas sim como a agenda da coalizão "a agenda do Executivo deixa de ser exclusivamente do Presidente e passa a refletir as preferências dos partidos que compõem a coalizão. Assim, [...] esta agenda descrita como sendo do presidente é na verdade da maioria” (Freitas, 2016, p.60). Dessa forma, a produção legislativa conta com a maioria ${ }^{6}$ dos parlamentares.

\footnotetext{
${ }^{6}$ Aqui retrata-se maioria, mas pode haver governos minoritários. 
Sendo assim, o Executivo compartilha a agenda com a sua coalizão e domina a maior parte do processo legislativo. Dentre esse domínio uma parte se configura pelo uso das MPs e do Pedido de Urgência, tais poderes, em tese, o permitiriam contornar os desejos do Legislativo. Todavia, Freitas (2016) demonstrou que justamente as Medidas Provisórias e as pautas com Urgência são as que mais recebem modificações no Legislativo. Demonstrando que, as MPs não representam um poder unilateral, assim como a Urgência não enfraquece o poder do Legislativo. Dentro dessa nova configuração de agenda, é visto significativa atuação dos parlamentares, tendo eles, segundo Freitas (2016), 36\% em média de atuação na produção legislativa. Ou seja, dentro da agenda compartilhada, o Legislativo altera parte significativa das PL, PLP e MPs iniciadas pelo executivo.

A recente literatura de Estudos Legislativos (Almeida, 2015, 2019; Freitas, 2016) aponta para uma nova configuração, as comissões permanentes no pós-88 tornam-se espaços chave para atividades legislativas: possuindo poder conclusivo/terminativo, sendo espaço privilegiado de discussão e negociação das matérias, estas viraram lócus privilegiado de atuação parlamentar. Além disso, é obrigatório, no rito ordinário, que todos os Projetos de Lei (PL) passem pela comissão a qual lhe é designada. Dessa forma estudar a atuação das comissões é importante devido aos seus poderes negativos e positivos. Dentro disto é visto por Amaral (2011) o poder conclusivo das comissões da Câmara dos Deputados na $1^{\text {a }}$ Sessão Legislativa da $50^{\mathrm{a}}$ legislatura. A autora demonstra que é $91 \%$ superior as rejeições feitas pelas comissões em relação ao Plenário, dentre essas, $63 \%$ são rejeitadas pelas comissões de mérito e as outras $37 \%$ de rejeitadas fazem jus as Comissões de Constituição e Justiça e de Cidadania e a de Finanças e Tributações, que dizem respeito a admissibilidade das pautas. Ou seja, as comissões da Câmara baixa apresentam forte uso do poder negativo.

Outro possível resultado negativo das comissões é o poder da não decisão, isto é, elas têm como possibilidade a não decisão sobre os projetos a elas enviados. Duas hipóteses são levantadas por Amaral (2011): a primeira argumenta que o grande número de matérias para a apreciação dificulta a análise da totalidade e a segunda fala que realmente existe esse poder de não decisão, haja vista também dos poderes de urgência. $\mathrm{O}$ fato é, existem matérias que são arquivadas por regimento e esse número é expressivo, a autora demonstra que cerca de $30 \%$ dos projetos que tramitaram na $50^{\mathrm{a}}$ legislatura foram arquivados pelo regimento devido à falta de parecer das comissões.

Outro argumento sobre o poder das comissões é o feito por Freitas (2016). Por não ter um poder negativo comparável com as comissões estadunidenses, as comissões brasileiras são vistas como fracas por parte da literatura. Todavia, a análise da autora (Freitas, 2016) permite demonstrar empiricamente que existe o poder positivo das comissões: no recorte de 1988 a 2010, 45\% das 
proposições que foram transformados em lei tiveram parecer nas comissões. Além disso, das $22 \%$ propostas transformadas em lei que tiveram pedido de urgência foi após a tramite ordinário pelas comissões, sendo a urgência usada para acelerar a pauta. Assim, é visto que as comissões têm função chave no processo legislativo, e nas alterações feitas por essas é observado que "PLs e PLPs são alterados majoritariamente no interior das comissões: respectivamente, $62 \%$ e $80 \%$ dos dispositivos do Legislativo não só foram apresentados no interior das comissões, como também passaram por deliberação no interior das mesmas" (Freitas, 2016, p.80).

\section{REFERÊNCIAL TEORICO}

Para se iniciar a discussão sobre Comissões parte-se da análise das três teorias política positiva sobre o Legislativo estadunidense: distributivista, informacional e partidário. Tais modelos partem do princípio da lógica da ação racional, apontando que o parlamentar, uma vez eleito, tem como objetivo se reeleger. Dessa forma, "todas elas têm como premissa o individualismo metodológico. Partem da ideia de que os indivíduos agem buscando maximizar seus interesses e que os parlamentares, em particular, buscam em primeiro lugar assegurar a sua reeleição" (Rocha e Barbosa, 2008, p.94).

O modelo distributivista parte da lógica da ação individual. Como o parlamentar individual não tem grande influência nas tendências nacionais, o mesmo tende a buscar recursos localistas. Dessa forma, o parlamentar busca alocar recursos para sua zona eleitoral, assim assegurando a sua reeleição.

Partindo de Meyhew, Rubiatti (2019, p. 14) aponta quatro estratégias referente aos métodos para reeleição no modelo distributivista:

advertising: estratégias usadas pelos parlamentares para se fazer conhecidos; 2) creditclaiming: reivindicar crédito pelas políticas adotadas 2 ; 3) position taking: tomar posição pública sobre matéria de interesse de seus eleitores; e 4) utilização da própria estrutura organizacional do Congresso (em especial, os gabinetes e as comissões) para otimizar a relação com seus eleitores.

Sendo assim, o congresso estaria organizado para efetivar a atuação desses parlamentares. O local onde tais ações seriam maximizadas são as comissões, sendo cada um lócus de áreas temáticas distintas, os parlamentares ocupariam de acordo com sua finalidade eleitoral. Assim, cada comissão seria composta por membros com preferencias extremas, homogênea e distante do mediano do 
plenário e, "como todas as comissões apresentariam essas características, haveria uma espécie de acordo tácito no qual nenhum parlamentar de uma comissão interferiria, ou se colocaria contrário, ao que foi decidido em outra comissão" (Rubiatti, 2019, p.14).

No tocante a teoria informacional o princípio do qual ela parte é a incerteza: o parlamentar diante decisão sobre determinadas políticas necessita de informação que demandam experiência e conhecimento técnico para a tomada de decisão, evitando resultados adversos. Dessa forma o Legislativo busca fomentar a geração de expertise com o intuito de diminuir incertezas, além disso o arranjo deve incentivar este ator a compartilhar a informação gerada. Em suma, "a geração de expertise, acompanhada do compartilhamento de informações, acaba por beneficiar a todos os parlamentares, uma vez que diminui a incerteza na tomada de decisão" (Rubiatti, 2019, p.15)

Assim, o local onde se geraria expertise seriam as comissões, o sistema tende a fortalecer a obtenção de informação para as comissões (por serem espaços temáticos privilegiados) e estas a fornecer informação para o plenário. Assim, partindo da proposta de Krehbiel

1) as comissões não serão compostas por altos demandantes ou membros com preferências extremas, uma vez que isso acarretaria ineficiência informacional, e as escolhas favoreceriam demasiadamente seus membros; 2) há possibilidade, excepcionalmente, de membros com preferências extremas comporem as comissões, porém apenas se os custos de especialização desses membros forem menor que a perda informacional que acarretam; 3) a comissão será heterogênea em sua composição, garantindo maiores ganhos informacionais; 4) haverá regras restritivas, reforçando as comissões frente ao plenário, garantindo primazia para as primeiras, uma vez que, com isso, se gera maiores incentivos para a especialização (Rubiatti, 2019, p.14).

A última abordagem é a partidária, nesta o princípio é que os partidos permitem ganhos internos e externos, sendo eles capazes de: resolução de problemas de ação coletiva, facilitar a criação de coalizão e criar estímulos para a cooperação - para ganhos internos - e ganhos eleitorais proveniente da aprovação de boas políticas e reputação. Nesta abordagem os partidos podem influenciar as tendências nacionais decorrente da ação coletiva, diferente da perspectiva distributivista. Assim, os parlamentares poderiam tanto alocar recursos para suas localidades como influenciar tendências nacionais por meio da ação coletiva. É nesse ponto que entra o partido. (Rubiatti, 2019, p.15-16).

Neste modelo, o partido majoritário ao deter os principais postos chaves dentro do Legislativo obtém controle de agenda. Ou seja, ele tem o poder de determinar quais matérias serão votadas ou não. Assim, controlando a agenda, o partido põe em pauta os projetos que lhe garantiram boa reputação e adia aquelas que podem lhe custar votos e dissidências dentro do partido. 
O local onde ocorre esse controle de agenda são as Comissões, pois, partindo de Cox e MacCubbins, estas "seriam espaços privilegiados para o controle da agenda que chega ao plenário. Por esse motivo, a ocupação delas se daria de forma a garantir que os membros que apresentassem lealdade aos interesses da maioria do partido as ocupassem" (Rubiatti, 2019, p.16). Dentro disso, "a abordagem destaca o papel da liderança. Esta deve possuir recursos para premiar e punir parlamentares de acordo com a orientação do partido, garantido assim a disciplina e reputação dentro do partido" (Rubiatti, 2019, p.16).

Assim, torna-se possível observar e analisar o comportamento das comissões. Vale ressaltar que "as [...] teorias positivas da organização legislativa norte-americana não são universalmente traduzíveis para qualquer contexto institucional, mas são suficientemente robustas e flexíveis para serem adaptadas sob alguma parcimônia a outros cenários institucionais" (Nascimento, 2013, p.62). Assim, é válida a utilização desses modelos como norteadores para a análise das comissões do Congresso brasileiro.

\section{METODOLOGIA}

Para sua realização, este trabalho foi dividido em duas partes: 1- tipos de reuniões que ocorreram na Comissão, 2- Pareceres feitos pelos relatores sobre Projetos de Lei (PL) e Sugestões Legislativas (SUG) que foram votados pela $\mathrm{CDH}$, cobrindo do seu ano de criação até a última legislatura completa (2005-2018). Os dados foram coletados nas plataformas do site do Senado Federal e nos Relatórios Anuais da Presidência (RAP).

Além disso, é utilizado a base de dados sobre as coalizões do CEBRAP, para as discussões que envolvem a participação da coalizão governista. Assim, se obtém um panorama mais claro sobre a participação dos partidos, governo e oposição na comissão.

No tocante a primeira parte, foram realizadas 1042 reuniões pela comissão. Destas, foram divididas em informacionais e deliberativas. Sendo as audiências públicas, reuniões de trabalho e reuniões divididas em duas partes (deliberativas e audiência pública) foram classificadas na categoria informacional. As reuniões deliberativas, orçamentarias e reuniões com duas seções (deliberativa e audiência pública) foram classificadas como deliberativas. Essa divisão em duas categorias tem como objetivo demonstrar as duas funções que são designadas as comissões, a de gerar informação (informacional) e de produzir relatórios e decidir sobre os projetos a ela destinado (deliberativa). 
Referente a segunda parte, foram analisados 640 projetos que tiveram relatórios votados na Comissão, que foram divididos em 1) as PL, SUG, Projeto de Lei Complementar (PLP), Emenda da Câmara dos Deputados à projetos do Senado (ECD), Substitutivos da Câmara dos Deputados à projetos do Senado (SCD); 2) órgão propositor: Executivo, Câmara dos Deputados, Senadores, Sociedade Civil; 3 ) partido de origem do propositor do projeto e seu pertencimento ou não à coalizão de governo; 4) partido de origem do relator do projeto e seu pertencimento ou não à coalizão de governo; 5) resultado indicado pelo relator e 6) resultado da votação do relatório na $\mathrm{CDH}$.

Com estes dados é possível demonstrar o comportamento, as funções realizadas pela Comissão e sua produção legislativa. Assim, contribuindo para uma melhor compreensão do funcionamento do processo legislativo brasileiro em uma comissão.

\section{PRODUÇÃO LEGISLATIVA DA CDH}

Visto que as comissões são lócus deliberativos, por deter produção, retenção e alteração das matérias, estudar a atuação destas se torna necessário. $\mathrm{O}$ primeiro ponto a destacar seria a sua composição. "A escolha de parlamentares para integrar as comissões está centralizada nas mãos dos líderes partidários. A rigor, as normas vigentes determinam que as designações sejam feitas pela Mesa Diretora, ouvidos os líderes dos partidos" (Santos, 2002, p.250). Além disso, o RISF determina que as vagas nas comissões possuam proporcionalidade com as cadeiras em plenário, assim cada partido indica o parlamentar para determinada comissão baseada na sua proporcionalidade e interesse na atuação da instituição. Na CDH é apontado por Souza e Silva (2019) alta fragmentação partidária chegando a ter 15 partidos na composição da $\mathrm{CDH}$, com taxa significativa de participação do PT e PMDB/MDB nos 14 anos analisados da comissão - tendo 20,7\% e 20\% respectivamente.

Das reuniões realizadas pela comissão, 763 se categorizam como informacional e 370 como deliberativa. Assim, é notável que predominantemente ocorrem reuniões informacionais, tal fato pode corroborar a teoria informacional. Uma vez que o parlamentar tem de decidir sobre múltiplas políticas que demandam conhecimento técnico e as audiências públicas seriam o principal meio para obter conhecimento sobre distintas pautas. Assim, "nas comissões são mais amplas as oportunidades de exame e debate. É onde se realizam audiências públicas, para se ouvir especialistas, e as discussões são abertas à participação de parlamentares individuais" (Almeida, 2019, p. 405). Dessa forma, a $\mathrm{CDH}$ demonstra empenho em ganhos informacionais. 


\section{GRÁFICO 1 - TIPOS DE REUNIÃO}

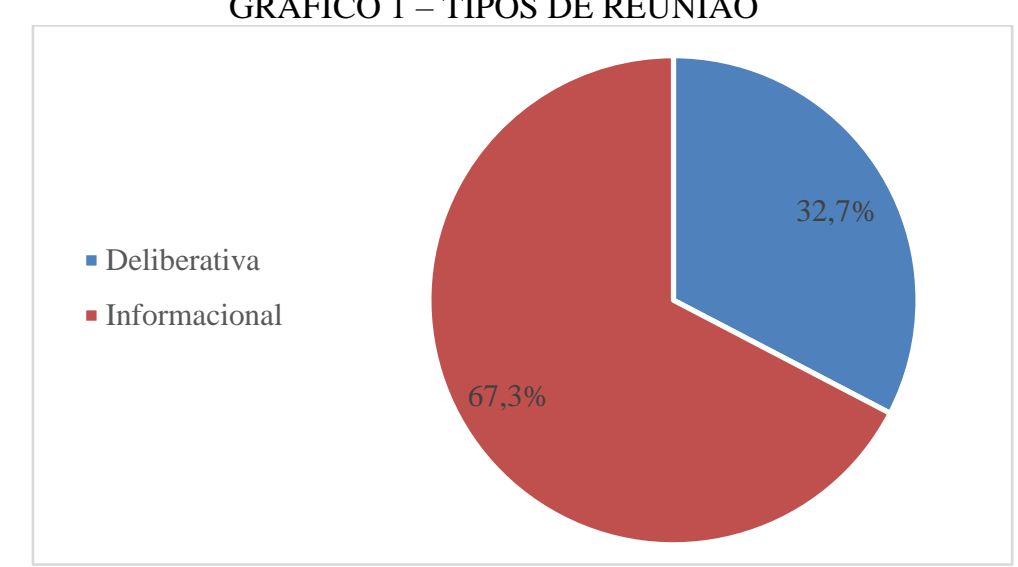

Fonte: elaboração própria a partir dos dados do site do Senado Federal.

Um segundo ponto a se destacar sobre a atuação da $\mathrm{CDH}$ é o número de reuniões realizadas. A partir disso nota-se que a comissão apresenta alto grau de institucionalização, uma vez que o número de reuniões tem um crescimento efetivo no decorrer das legislaturas. A possibilidade de institucionalizar-se pode ser atribuída a capacidade das comissões de promover reuniões continuamente.

\section{GRÁFICO 2 - NÚMEROS DE REUNIÃO POR LEGISLATURA}

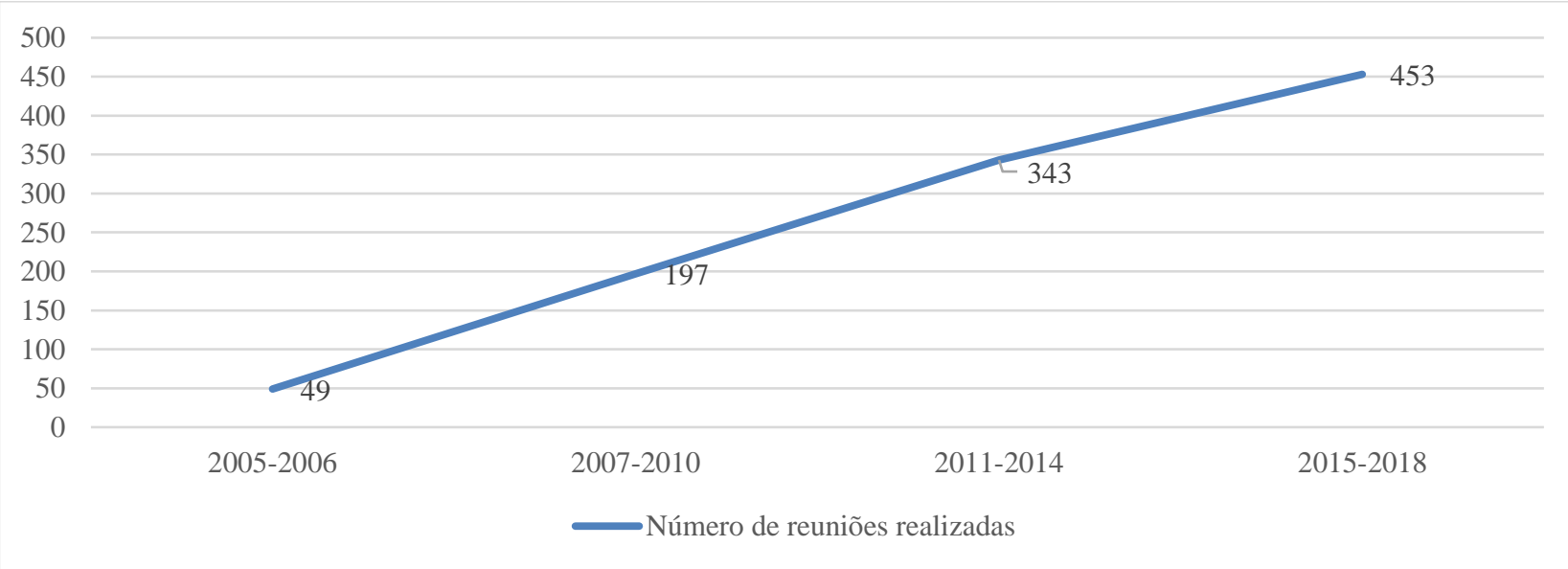

Fonte: elaboração própria a partir dos dados do site do Senado Federal.

Sobre os projetos que tramitaram na CDH, nota-se que os Projetos de Lei da Câmara (PLC) e Projeto de Lei do Senado (PLS) representam quase 74\% dos projetos que passaram pela comissão, seguidos dele vem as Sugestões (SUG) que fazem parte da legislação participativa da comissão e por último os Substitutivos e Emendas da Câmara dos deputados (SCD/ECD) que retratam o sistema de navette brasileiro. Vale ressaltar que, as Sugestões Legislativa apresentam significativa taxa, o que demonstra a participação da Sociedade Civil dentro dos projetos analisados pela CDH, estes 
representam quase um quarto dos projetos que tramitaram pela comissão, o que é uma frequência significativa.

TABELA 1 - ORIGEM DOS PROJETOS QUE TIVERAM PARECER NA CDH

\begin{tabular}{cc}
\hline Propositor & Porcentagem \\
\hline Senadores & 58,4 \\
Deputados & 16,1 \\
Executivo & 1,4 \\
Sociedade Civil & 24,1 \\
\hline
\end{tabular}

Fonte: elaboração própria a partir dos dados do site do Senado Federal.

Sobre origem dos projetos que tiveram parecer na comissão, há predominância de projetos de origem dos senadores. Visto que Senado e Câmara possuem o mesmo poder de proposição é esperado que a casa também inicie matérias. Porém, os projetos iniciados por deputados já teriam passado por um filtro na própria câmara de origem, enquanto que o mesmo ainda não ocorreu com os projetos dos senadores.

A segunda maior frequência é de projetos de origem da Sociedade Civil, as sugestões (SUG) se aprovadas $^{7}$ se tornam PLs de autoria da comissão e representam a parte da Legislação Participativa da CDH. No tocante aos Deputados, é notável uma participação significativa, visto que as PLC já passaram pelo filtro da própria Casa e seguem o rito bicameral, ou seja, esperam o parecer do Senado.

É importante destacar também as proposições do Executivo, sendo 1,4\% (9 projetos) apresentados durante todo período analisado. Sendo 8 vezes relatado por membro da coalizão (7 no governo Dilma I e 1 no Temer) e 1 vez por um partido de fora da coalizão da coalizão (Dilma II em 2014), porém, o partido desse relator era o PSB, que havia participado anteriormente da coalizão. Dessas propostas, 8 foram aprovadas e 1 foi apresentada emenda - relatório feito pela senadora Ana Rita do PT.

Retirando as sugestões legislativas, vê-se de uma forma como o Senado é preponderante nas proposições avaliadas pela $\mathrm{CDH}$, com o total $77 \%$ das proposições sendo dos senadores. Essa preponderância pode estar relacionada a inexistência de filtragem prévia dos projetos dos Senadores, que, ao contrário dos projetos dos deputados e do Executivo, não foram avaliados ainda em nenhuma outra casa legislativa. Referente os Deputados, a taxa se torna $21,2 \%$, ficando mais claro sua participação na comissão. Desta forma, os projetos são quase exclusivamente de origem legislativas.

\footnotetext{
${ }^{7}$ as Sugestões são realizadas pelo site do próprio Senado Federal por qualquer pessoa que acessar a seção da Legislação participativa. Feito a sugestão, esta necessita de o quórum mínimo de 20.000 mil assinaturas on-line elas entrar na pauta do Senado. Após isso, ela entra na $\mathrm{CDH}$ e espera ser designada a um relator.
} 
Aqui demonstra-se o interesse do Legislativo pela temática da $\mathrm{CDH}$, tal interesse pode estar relacionado ao modo como se distingue as pautas. É apontado que o Executivo domina as pautas de ordem administrativas, orçamentarias e de impacto nacional e o Legislativo cuida das pautas de ordem social. Segundo Araújo (2008, p. 214), “os projetos da área social são os preferidos dos legisladores, seguidos dos econômicos e administrativos - merece destaque o fato de que a ordem de preferência por temas é a mesma para as duas casas" (Araújo, 2008, p.214).

TABELA 2 - RESULTADOS DOS PARECERES, INCLUINDO SUG

\begin{tabular}{ccccc}
\hline Aprovado & Emenda/Substitutivo & Rejeitado & Arquivado & Prejudicado \\
\hline $42,88 \%$ & $34,90 \%$ & $12,99 \%$ & $5,48 \%$ & $3,76 \%$ \\
\hline
\end{tabular}

Fonte: elaboração própria a partir dos dados do site do Senado Federal.

Referente aos resultados dos pareces feitos na comissão, observa-se que a maior parte destes é pela aprovação, com $43 \%$ de frequência, sendo a segunda maior taxa a de emendas/substitutivos com 35\%. Também há notável uso da rejeição com 13\%, arquivados representam 5\% e prejudicados 4\%. Assim se observa que a comissão utiliza nitidamente o seu poder positivo, de aprovar e alterar matérias. Aqui vale ressaltar que são contabilizados os 640 pareceres feitos pela comissão, com as PLS/PLC, SCD/ECD, SUG e matérias do Executivo.

Ponto importante a destacar, é que mesmo havendo iguais destinos de resultados, há diferença na tramitação nas SUG. Por serem oriundas da Sociedade Civil, estas necessitam da aprovação dentro da comissão como SUG para se tornar PLS - se torna PLS de autoria da comissão - e passa pelo tramite com os demais projetos de lei.

Como observado na tabela 1 as SUG ocupam 24\% das proposições que passam pela comissão, assim os resultados destas alteram os dados referente aos resultados dos parecerem efetivos ${ }^{8}$, assim se torna necessário analisar os resultados sem o peso das sugestões.

TABELA 3 - RESULTADOS DOS PARECERES, EXCLUÍDAS AS SUGS

\begin{tabular}{ccccc}
\hline Aprovado & Emenda/Substitutivo & Rejeitado & Arquivado & Prejudicado \\
\hline 39,09 & 45,68 & $10,70 \%$ & $0,41 \%$ & $4,12 \%$ \\
\hline
\end{tabular}

Fonte: elaboração própria a partir dos dados do site do Senado Federal.

Observado os resultados dos pareceres sem as sugestões legislativa, é visto que a maior taxa se encontra nas emendas/substitutivos, que são as mudanças que ocorrem nas matérias dentro da comissão, demonstrando assim a atuação como órgão deliberante. Também se nota uma presença

\footnotetext{
${ }^{8}$ Visto que as SUGs ao serem aprovadas não se tornam leis ou seguem para o plenário da Casa, mas sim se tornam projetos que terão que ser ainda analisados.
} 
significativa de projetos aprovados sem alteração pela comissão $(39,09 \%)$. Dessa forma, nota-se um forte poder positivo da CDH e baixa utilização de rejeição e arquivamento pelas mesmas, reforçando a imagem da comissão não como um forte poder de veto, mas atuando de forma a alterar e dar prosseguimento as propostas por ela analisada.

TABELA 4 - PROJETO DE LEI POR PARTIDO PROPOSITOR (PORCENTAGEM)

\begin{tabular}{cccc}
\hline Partido & PLS & PLC & PLS+PLC \\
\hline PT & 20,59 & 16,16 & 20,75 \\
MDB/PMDB & 11,76 & 17,17 & 13,47 \\
PSDB & 14,17 & 8,08 & 13,47 \\
PSB & 11,50 & 4,04 & 10,38 \\
PDT & 8,29 & 10,10 & 9,05 \\
DEM/PFL & 6,15 & 5,05 & 6,18 \\
PL/PR & 4,81 & 2,02 & 4,86 \\
PTB & 4,81 & 3,03 & 4,64 \\
PCdoB & 3,21 & 4,04 & 3,53 \\
PP & 3,48 & 3,03 & 3,53 \\
PRB/PMR & 2,94 & 1,01 & 2,65 \\
PPS & 1,07 & 3,03 & 1,55 \\
PSC & 1,34 & 1,01 & 1,32 \\
PV & 0,53 & 5,05 & 1,55 \\
PODEMOS & 1,34 & 0,00 & 1,10 \\
PSD & 0,00 & 3,03 & 0,66 \\
PROS & 0,27 & 0,00 & 0,22 \\
REDE & 0,53 & 0,00 & 0,44 \\
PSOL & 0,27 & 0,00 & 0,22 \\
PTC & 0,00 & 1,01 & 0,22 \\
S/P & 0,27 & 0,00 & 0,22 \\
\hline
\end{tabular}

Fonte: elaboração própria a partir dos dados do site do Senado Federal.

Nesta tabela, foram destacadas 453 proposições feitas pelos partidos, excluídos as proposições do Executivo, Comissões e SUGs. Nota-se que o partido que fez mais projetos de leis foi o PT, seguido por PSDB e PMDB/MDB, sendo os três maiores propositores.

Sobre a ampla participação dos partidos nas proposições, destaca-se que isso é resultado do próprio regimento interno, pois cabe ao Senador individual "I - oferecer proposições, discutir, votar e ser votado" (RISF, 2019). Dentro disso, é notável que a maior frequência de proposições pertence ao PT, com 20,75\%, seguido do PMDB/MDB, PSDB os 3 partidos juntos ocupam mais de 47,69\% das proposições da comissão.

TABELA 5 - INDICAÇÃO DO RELATÓRIO POR PARTIDO PROPOSITOR (PORCENTAGEM)

\begin{tabular}{cccccc}
\hline Partido & Aprovado & Emenda/Substitutivo & Rejeitado & Prejudicado & Arquivado \\
\hline PT & 38,3 & 55,3 & 5,3 & 1,1 & 0,0 \\
PSDB & 32,8 & 45,9 & 9,8 & 11,5 & 0,0 \\
PMDB/MDB & 39,3 & 42,6 & 13,1 & 4,9 & 0,0 \\
PSB & 48,9 & 46,8 & 4,4 & 0,0 & 0,0 \\
PDT & 24,4 & 56,1 & 12,2 & 7,3 & 0,0 \\
\hline
\end{tabular}




\begin{tabular}{cccccc}
\hline DEM/PFL & 28,6 & 42,9 & 21,4 & 7,1 & 0,0 \\
PL/PR & 13,3 & 50 & 22,7 & 13,6 & 0,0 \\
PTB & 38,1 & 57,1 & 4,8 & 0,0 & 0,0 \\
PP & 37,5 & 37,5 & 25 & 0,0 & 0,0 \\
PCdoB & 43,8 & 43,8 & 6,3 & 0,0 & 6,3 \\
PRB/PMR & 50 & 41,7 & 8,3 & 0,0 & 0,0 \\
PPS & 42,9 & 57,1 & 0,0 & 0,0 & 0,0 \\
PV & 57,1 & 42,9 & 0,0 & 0,0 & 0,0 \\
PSC & 33,3 & 50 & 16,7 & 0,0 & 0,0 \\
PODEMOS & 80 & 20 & 0,0 & 0,0 & 0,0 \\
PSD & 66,7 & 33,3 & 0,0 & 0,0 & 0,0 \\
REDE & 50 & 0,0 & 0,0 & 50 & 0,0 \\
PSOL & 100 & 0,0 & 0,0 & 0,0 & 0,0 \\
PROS & 0,0 & 100 & 0,0 & 0,0 & 0,0 \\
PTC & 0,0 & 100 & 0,0 & 0,0 & 0,0 \\
S/P & 100 & 0,0 & 0,0 & 0,0 & 0,0 \\
\hline Total & 37,3 & 48,1 & 9,9 & 4,4 & 0,2 \\
\hline
\end{tabular}

Fonte: elaboração própria a partir dos dados do site do Senado Federal.

Na tabela 5 é visto a indicação dos relatórios por partido propositor. Ou seja, qual foi o parecer dado pelo relator as matérias de acordo com o partido. $O$ total nesta tabela, difere da tabela 2 devido a exclusão dos projetos do Executivo, Comissões, ECD e $\mathrm{SCD}^{9}$ por motivos de contabilizar somente os partidos. É nítido que quase metade de todas as proposições passam por alteração no interior da comissão $(48,1 \%)$, assim como pela aprovação com $37,3 \%$, o que retrata o poder positivo da comissão de aprovar e alterar as propostas.

Importante ressaltar, que o partido do Executivo é o que detém a maior taxa de proposição e apresenta uma das maiores taxas de alterações. Porém, ser propositor não carrega nenhum poder em si. Assim, das 52 proposições que foram alteradas do PT, 27 são feitas por relatores de outros partidos e 25 dele mesmo. Dessa forma, quase metade das alterações são cunho partidário.

Referente ao PSDB, partido de oposição aos governos Lula e Dilma, há 28 propostas com alteração, destas 11 são relatadas pelo PT. Assim se observa que há controle partidário também nas propostas da oposição pelo partido do Executivo. Vale destacar que, das alterações feitas nas propostas do PSDB somente 5 foram realizadas pelo próprio partido.

\footnotetext{
${ }^{9}$ Salvo exceção o SCD 66/1999 que tem como propositor o Deputado Eduardo Suplicy. 


\section{GRÁFICO 3 - PARTICIPAÇÃO DA COALIZÃO NA PROPOSIÇÃO DE PROJETOS VOTADOS NA CDH}

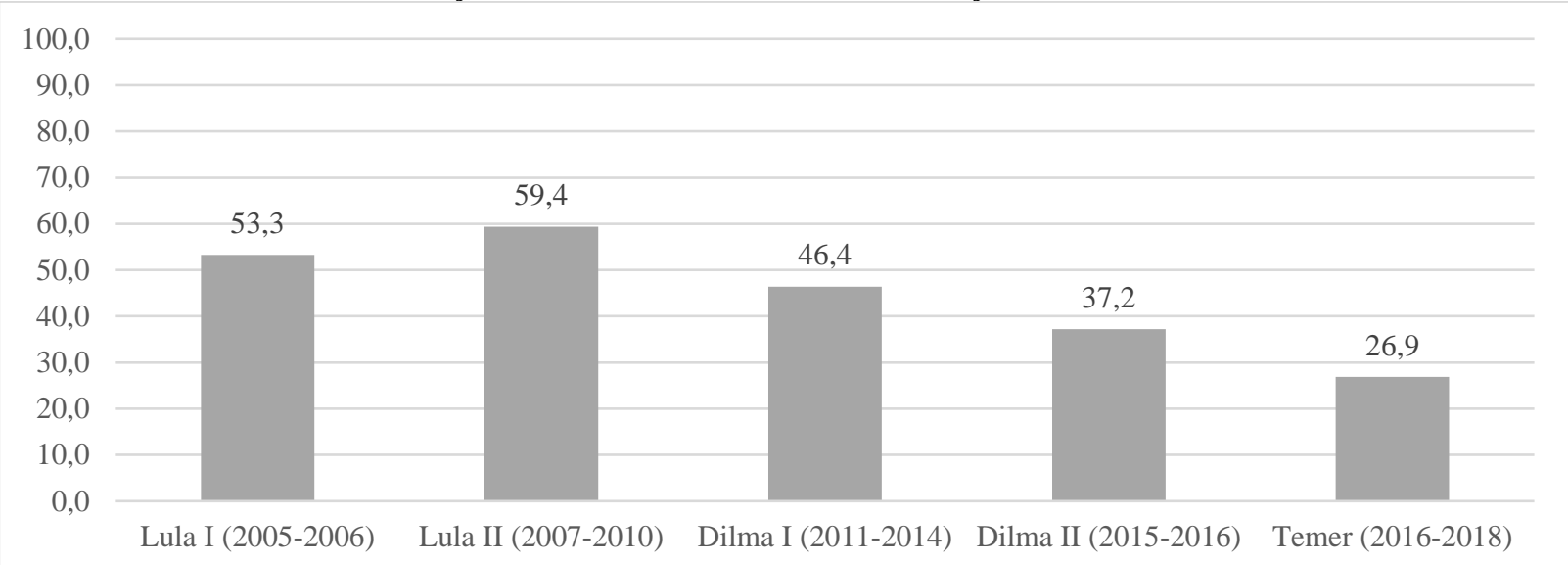

Fonte: elaboração própria a partir dos dados do site do Senado Federal.

No gráfico 3 se observa a participação dos partidos membros da coalizão ${ }^{10}$ nas proposições que chegaram a CDH. Nele, é nítida a participação dos membros da coalizão dos governos Lula I e Lula II, com ambas sendo mais da metade das proposições. Essa frequência, tem grande declínio nos mandatos Dilma I e Dilma II chegando a obter sua menor participação no governo Temer. Tais dados demonstram um princípio de crescimento de proposições feita pela base governista, que depois diminui e chega a 26,9\% no final do governo Temer.

Vale destacar que nos quatro governos do PT há o declínio na participação em proposição, isso pode ocorrer porque os ganhos políticos por proposição nessa área temática podem ser baixos, desincentivando os membros da coalizão de atuarem sobre ele. Assim é visto a queda na frequência de proposição pela base do governo.

No tocante ao governo Temer, esta é a menor taxa de proposições feitas. O que ressalta que as demais proposições vieram de fora da coalizão podendo ser possíveis opositores ao governo, ou partidos não membros da coalizão. Dessa forma, deixar a oposição ou partidos não membros da coalizão agir pode demonstrar a falta de interesse do Executivo pela área temática da comissão, o que configura que a pauta deste governo não está ligada aos Direitos Humanos como objetivo principal.

Dessa forma, observasse que a baixa taxa de proposição do Executivo sinalizada na tabela 1 acompanha o interesse da coalizão em propor, ou seja, há um princípio de delegação de função entre Executivo e coalizão, porém essa frequência tem decrescido nas Legislaturas.

\footnotetext{
${ }^{10}$ Cada governo possui mais de uma coalizão. Por isso, os dados foram originalmente organizados tendo por base os anos de vigência de cada coalizão. Após isso, foram somados os projetos de cada coalizão para dar o número total das propostas da coalizão por mandato.
} 
TABELA 6 - RESULTADOS DOS PROJETOS PROPOSTOS PELA COALIZÃO NA CDH

\begin{tabular}{cccccc}
\hline & Lula I & Lula II & Dilma I & Dilma II & Temer \\
& $(2005-2006)$ & $(2007-2010)$ & $(2011-2014)$ & $(2015-2016)$ & $(2016-2018)$ \\
\hline Aprovado & 43,8 & 39,5 & 36,5 & 27,6 & 26,2 \\
Emenda/substitutivo & 50,0 & 51,3 & 47 & 58,6 & 57,1 \\
Rejeitado & 6,2 & 9,2 & 11,3 & 6,9 & 9,5 \\
Prejudicado & & & 5,2 & 3,4 & 7,1 \\
Arquivado & & & 3,4 & \\
\hline
\end{tabular}

Fonte: elaboração própria a partir dos dados do site do Senado Federal.

Aqui foram analisados os relatórios sobre as matérias de origem da coalizão governamental. Ou seja, quais foram os resultados propostos nos relatórios referentes aos projetos da base do governo. Vale destacar, que não é exclusivo o posto de relator à base, assim, projetos da base do governo podem ser relatados por não membros da coalizão e até mesmo pela oposição.

Referente aos resultados dos projetos propostos pela coalizão, é visto que de todas as legislaturas a maior frequência encontra-se nas emendas/substitutivos. Ou seja, mesmo sendo propostas da base elas são modificadas no interior do Legislativo. Assim, a participação da comissão nas propostas da coalizão é nítida, havendo alterações nas matérias que chegam à comissão.

TABELA 7 - RELATORES POR PARTIDO (PORCENTAGEM)

\begin{tabular}{ccccc}
\hline Partido & SUG & PL & ECD/SCD & TOTAL \\
\hline PT & 51,30 & 48,41 & 76,92 & 79,69 \\
PSDB & 1,95 & 8,67 & 7,69 & 6,09 \\
PDT & 7,79 & 5,71 & 0,00 & 6,09 \\
PV & 4,55 & 6,77 & 0,00 & 5,78 \\
PMDB/MDB & 6,49 & 5,71 & 0,00 & 4,84 \\
PSB & 2,60 & 5,29 & 15,38 & 3,28 \\
PTB & 6,49 & 2,33 & 0,00 & 3,28 \\
PSD & 4,55 & 2,96 & 0,00 & 2,50 \\
PL/PR & 5,19 & 1,69 & 0,00 & 2,50 \\
DEM/PFL & 1,30 & 2,96 & 0,00 & 2,19 \\
PSC & 1,30 & 2,54 & 0,00 & 1,25 \\
PRB/PMR & 0,65 & 1,69 & 0,00 & 0,09 \\
PODEMOS & 1,30 & 1,06 & 0,00 & 0,94 \\
PP & 1,30 & 0,85 & 0,00 & 0,78 \\
PSOL & 0,65 & 1,06 & 0,00 & 0,47 \\
PPS & 1,30 & 0,63 & 0,00 & 0,31 \\
PROS & 0,65 & 0,42 & 0,00 & 0,31 \\
PCdoB & 0,65 & 0,21 & 0,00 & 0,31 \\
PMN & 0,00 & 0,42 & 0,00 & 0,16 \\
S/P & 0,00 & 0,42 & 0,00 & 0,00 \\
PMB & 0,00 & 0,21 & 50, &
\end{tabular}

Fonte: elaboração própria a partir dos dados do site do Senado Federal.

Nesta tabela, foram contabilizados todos os matérias que passaram pela CDH. Assim, há 640 projetos que foram relatadas na $\mathrm{CDH}$, o importante a destacar é que 318 foram relatadas pelo PT, o que torna este partido o principal relator da comissão. O segundo partido com maior relatoria é o PSDB com 45, que é oposição dos governos Lula e Dilma e se torna base no governo Temer. Disto, 
é importante ressaltar que o PSDB não obteve nenhuma relatoria no governo que foi base, e possui a segunda maior frequência de relatórios enquanto partido de oposição.

Visto a importância dada ao cargo de relator pelo PT, vale ressaltar o porquê disto. Tal importância dada ao cargo deriva do seu poder de agenda, pois

no parecer, o relator tem liberdade para aceitar, rejeitar e emendar a proposição inicial ou, até mesmo, acatar as sugestões apresentadas por outros parlamentares. Ademais, se não estiver suficientemente convencido a respeito das consequências da aprovação da proposição, o relator pode requerer, dentro do prazo que lhe é concedido, a realização de audiências públicas para debater o conteúdo da proposição. (Aguiar, 2013, p.149)

Destacando que, o cargo de relator é designado pela presidência da comissão, e visto que na CDH este cargo esteve nas mãos do PT por longo período - segundo Souza e Silva (2019) o PT ocupou $66,7 \%$ o posto de presidente na comissão - é esperado esse controle nas relatorias pelo partido.

Assim, o cargo de relator possui grande poder de agenda, uma vez que como agente informacional ele tem o poder de influenciar o caminho que a matéria irá seguir, assim como agente partidário ele pode defender o interesse do partido garantindo a boa reputação do partido. Dessa forma, é visto o destaque que os partidos dariam a este cargo chave.

TABELA 8 - INDICAÇÃO DO RELATÓRIO POR PARTIDO DO RELATOR (PORCENTAGEM) COM SUG

\begin{tabular}{|c|c|c|c|c|c|}
\hline Partido & Aprovado & Emenda/Substitutivo & Rejeitado & Prejudicado & Arquivado \\
\hline PT & 44,0 & 34,9 & 13,8 & 2,2 & 5,0 \\
\hline PSDB & 31,0 & 55,6 & 11,1 & 0,0 & 2,2 \\
\hline PV & 38,5 & 23,1 & 10,3 & 28,2 & 0,0 \\
\hline PDT & 52,6 & 36,8 & 0,0 & 5,3 & 5,3 \\
\hline PMDB/MDB & 37,8 & 35,1 & 18,9 & 0,0 & 8,1 \\
\hline PSB & 45,2 & 29,0 & 25,8 & 0,0 & 0,0 \\
\hline PSD & 38,1 & 38,1 & 14,3 & 4,8 & 4,8 \\
\hline PTB & 42,9 & 23,8 & 14,3 & 9,5 & 9,5 \\
\hline DEM/PFL & 43,8 & 37,5 & 6,3 & 6,3 & 6,3 \\
\hline PL/PR & 31,3 & 31,3 & 0,0 & 0,0 & 37,5 \\
\hline PSC & 71,4 & 21,4 & 0,0 & 0,0 & 7,1 \\
\hline PRB/PMR & 55,4 & 44,6 & 0,0 & 0,0 & 0,0 \\
\hline PODEMOS & 42,9 & 42,9 & 14,3 & 0,0 & 0,0 \\
\hline PP & 50,0 & 33,3 & 16,7 & 0,0 & 0,0 \\
\hline PSOL & 16,7 & 16,7 & 50,0 & 0,0 & 14,3 \\
\hline PPS & 20,0 & 40,0 & 40,0 & 0,0 & 0,0 \\
\hline PROS & 100,0 & 0,0 & 0,0 & 0,0 & 0,0 \\
\hline PCdoB & 50,0 & 0,0 & 0,0 & 0,0 & 50,0 \\
\hline $\mathrm{S} / \mathrm{P}$ & 0,0 & 100,0 & 0,0 & 0,0 & 0 \\
\hline PMN & 0,0 & 50,0 & 50,0 & 0,0 & 0 \\
\hline PMB & 100,0 & 0,0 & 0,0 & 0,0 & 0,0 \\
\hline TOTAL & 42,8 & 34,9 & 12,9 & 3,8 & 5,5 \\
\hline
\end{tabular}

Fonte: elaboração própria a partir dos dados do site do Senado Federal.

Aqui se observa, qual foi a indicação do relatório de acordo com o partido a que pertencem. Referente a isso, é visto que na totalidade os projetos aprovados são maiores que os com 
emendas/substitutivo, porém vale destacar que aqui estão inclusos os relatórios com parecer de SUGs, e como já destacado o rito desta diferencia-se das PLs. Assim, aqui se observa um quadro de uma comissão que atua de forma positiva no âmbito de aprovação e alteração.

Porém ao se retirar as SUGs, o quadro muda. Tendo 39,09\% de aprovados; emendas/substitutivos 45,68\%; rejeitados 10,70\%; prejudicados 4,12\%; arquivados $0,41 \%$. Alterando significativamente a proporção entre aprovados e emendas/substitutivos, demonstrando que a comissão corrobora o que trata a bibliografia enquanto atuação positiva, com grande número de alterações aos projetos sendo feitas em seu interior.

Destacando o controle feito pelas relatorias, o PT que esteve no cargo 318 vezes, relatou 49 propostas do próprio partido. Assim, é notável que o trabalho do partido foca nas proposições dos demais partido com 81 relatórios pela aprovação e 106 com emendas/substitutivo (excluído SUG). Assim, esse partido demonstra que, quando ocupa a relatoria altera mais que aprova.

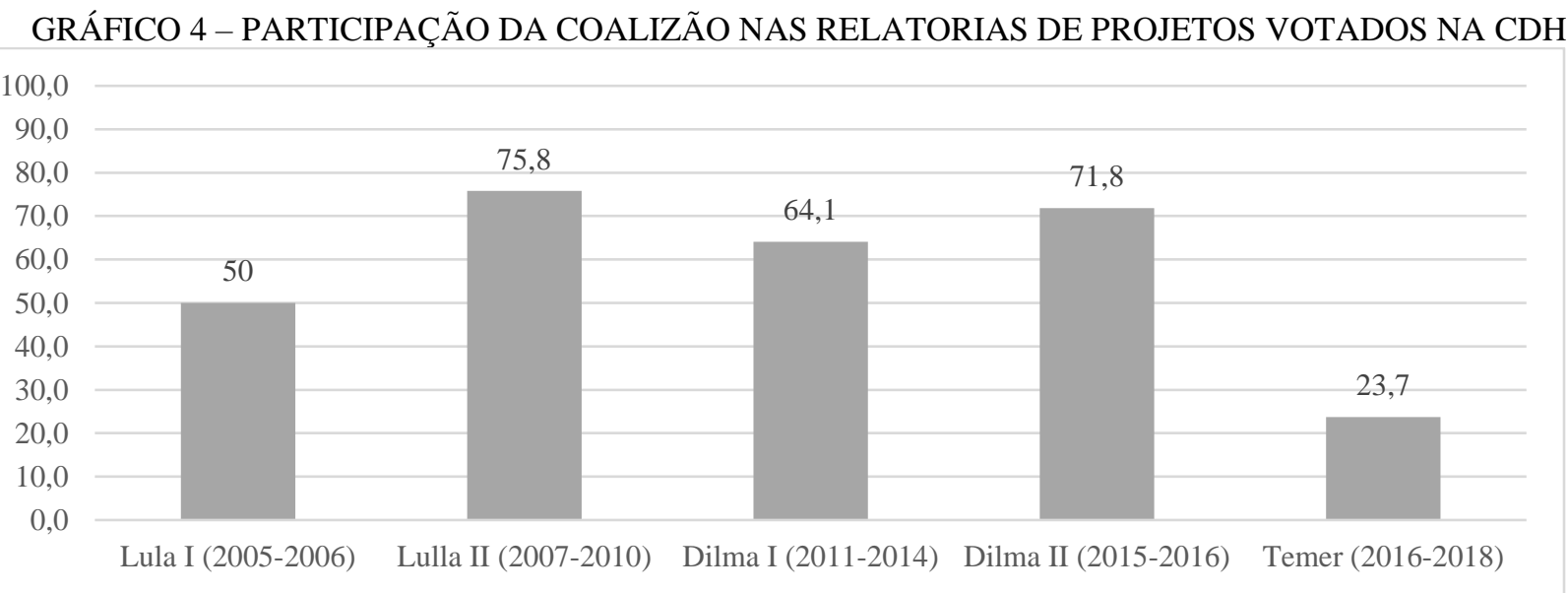

Fonte: elaboração própria a partir dos dados do site do Senado Federal.

Sobre a participação da coalizão nas relatorias, tem-se um quadro com mudanças nítidas, nos governos Lula I e II e Dilma I e II a participação dos partidos membros da coalizão é alta, sempre acima dos 50\% com o máximo em $75 \%$ no Lula II. Também é visto que a participação é maior nos segundos mandatos de Lula e Dilma. Tais dados demonstram o empenho da coalizão em participar das relatorias.

Referente ao governo Temer, com a menor taxa de relatoria, durante todo o seu mandando a CDH teve como presidente a senadora Regina Souza do PT. Sendo o presidente da comissão aquele que designa a relatoria das matérias é esperado esse controle das relatorias pelo partido. Dessa forma, ocupando a comissão, a presidência (Souza e Silva, 2019) e as relatorias, o PT teria grande capacidade de controle da agenda da área temática da $\mathrm{CDH}$, sendo um aspecto do modelo partidário: 
uma vez que esse partido tem capacidade de controlar a agenda e, ao exercer esse controle, consegue evitar que matérias, que irão dividir os votos do próprio partido, cheguem ao plenário - mantendo assim a boa imagem do partido -, e garantindo a preservação do status quo frente a políticas indesejáveis. (Rubiatti, 2019, p.16).

Assim, é perceptível o empenho do partido em controlar a pauta de Direitos Humanos no Senado, tendo predominância na presidência, relatorias, e ocupando a comissão.

TABELA 9 - INDICAÇÃO DOS RELATÓRIOS FEITOS POR MEMBROS DA COALIZÃO NA CDH

\begin{tabular}{cccccc}
\hline & Lula I & Lula II & Dilma I & Dilma II & Temer \\
& $(2005-2006)$ & $(2007-2010)$ & $(2011-2014)$ & $(2015-2016)$ & $(2016-2018)$ \\
\hline Aprovado & 26,7 & 44,3 & 47,8 & 44,6 & 48,7 \\
Emenda/substitutivo & 26,7 & 38,1 & 37,7 & 39,3 & 21,6 \\
Rejeitado & - & 5,2 & 12,6 & 5,4 & 24,3 \\
Prejudicado & - & - & 0,6 & 5,4 & - \\
Sobrestado & - & 1 & - & - & - \\
Arquivado & 46,6 & 11,3 & 1,3 & 3,6 & 5,4 \\
Outros & - & - & - & $1,7 *$ & - \\
\hline
\end{tabular}

*se refere ao relatório a SUG 8/2014, cujo o parecerista indica a criação de uma Subcomissão para tratar da sugestão. Fonte: elaboração própria a partir dos dados do site do Senado Federal.

Retratado a indicação dos relatórios por membros da coalizão por legislatura, observa-se que que a maioria dos resultados se encontra entre aprovado seguido por emenda/substitutivo. Vale destacar, que no Lula I o quadro seria de $50 \%$ aprovados e emendas/substitutivo, porém os arquivados com $46,6 \%$ retratam as SUG do período.

Em Lula II arquivados e sobrestados também representam resultados de SUG, tendo uma maior taxa de aprovação e em seguida emendas/substitutivos. Referente a Dilma I e II, obtém-se dados semelhantes em aprovação e alterações, sendo os arquivados de Dilma I Sugestões Legislativas. Nos governos Dilma aparecem uma taxa maior do poder negativo feito pelas relatorias.

No tocante ao governo Temer, a maior frequência de relatório feitos pelos membros da coalizão é pela aprovação, tendo emendas/substitutivo e rejeitado frequência similar. Esse crescimento da rejeição está relacionado com o propositor das matérias relatadas pela coalizão: no período Temer, apenas 16,2\% dos relatórios feitos por membros da coalizão eram de projetos apresentados por integrantes da própria coalizão. 83,8\% dos relatórios da coalizão eram sobre projetos iniciados por membros externos a coalizão ou a SUGs ${ }^{11}$.

\footnotetext{
${ }^{11}$ De fato, no período Temer, os membros da coalizão fizeram relatórios indicando a rejeição de nove projetos, sendo sete sobre Sugestões Legislativas e dois para projetos da oposição (PT e PCdoB).
} 


\section{GRÁFICO 5 - RESULTADOS DOS PARECERES POR LEGISLATURA}

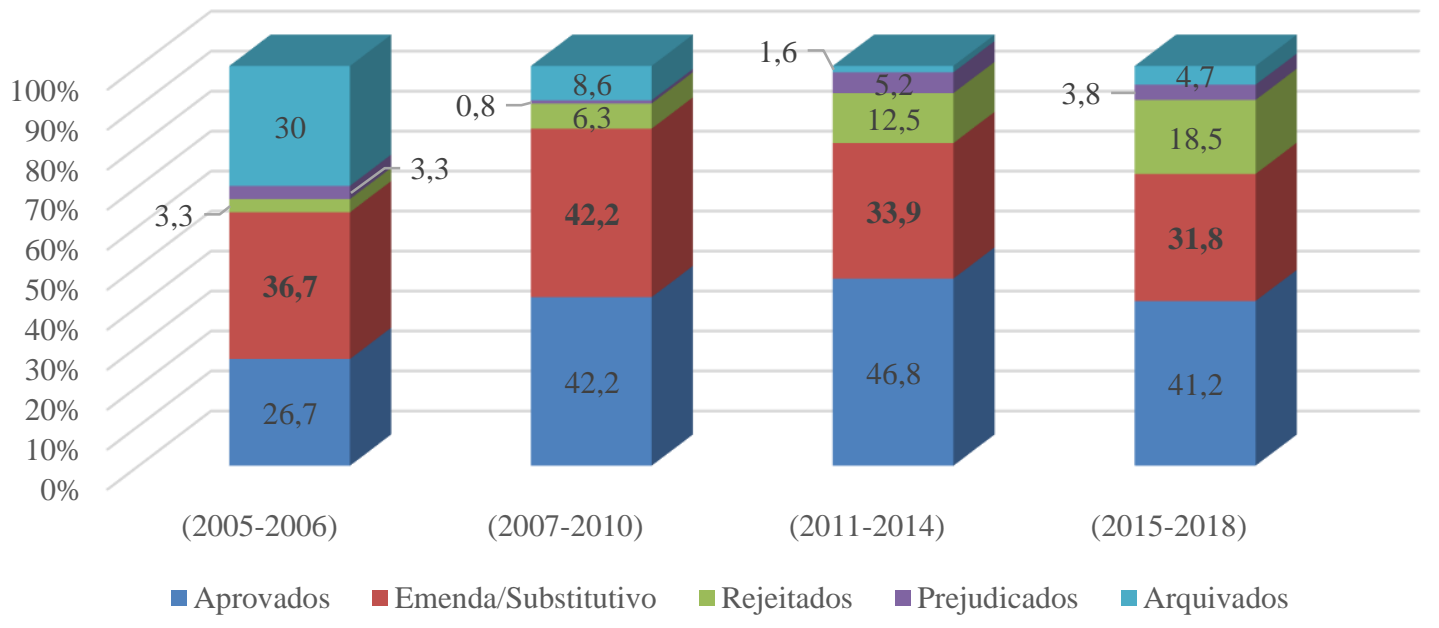

Fonte: elaboração própria a partir dos dados do site do Senado Federal.

No gráfico 5 se observa os resultados dos pareceres por legislatura. Os anos de 2005-2006 representa a criação da Comissão e por isto está somente com os dois anos. Observa-se grande taxa de emenda/substitutivo seguido de arquivados - único momento que os arquivados representam grande taxa haja visto que nestes anos somente 30 pareceres foram proferidos pela comissão e os 9 arquivados representam as SUG apresentadas - e sendo a terceira maior taxa de aprovados, sendo assim a primeira meia legislatura da comissão.

Seguido disto, em 2007-2010, há igual aprovação por relatórios de emendas/substitutivo e aprovados. Ou seja, grande poder positivo da comissão aprovando e alterando significativamente os projetos por elas analisados. Nesta legislatura foram feitos 128 pareceres, aqui há clara institucionalização da comissão, o que sinaliza os dados distintos da legislatura anterior.

Referente a 2011-2014, com 248 relatórios aprovados, a comissão apresenta maior frequência de relatórios pela aprovação, seguidos pelos de emendas/substitutivos. O que a diferencia da legislatura anterior é a maior taxa de resultados rejeitados e prejudicados, ou seja, há maior participação de resultados negativos aos projetos nesse período. Porém, ainda apresenta maiores resultados pelo poder positivo.

Sobre a última legislatura, com 234 relatórios, há leve queda na frequência de aprovados e modificados, mas eles permanecem predominantes enquanto pareceres na comissão. A frequência que teve ligeiro crescimento foi pela rejeição. O que demonstra o uso maior do poder negativo da comissão, que vem crescendo gradualmente nas legislaturas. Assim como que predominantemente a comissão aprova e altera as pautas que passa por ela. 


\section{CONSIDERAÇÕES FINAIS}

Tendo em vista que as comissões são lócus de deliberação no cenário pós-88, nota-se que a $\mathrm{CDH}$ acompanha essa lógica de funcionamento, pois ela apresenta crescente números de reuniões, e destas o caráter informacional é destacado. Ainda, é perceptível que majoritariamente passam por ela matérias de origem do Senado, o que fortalece a imagem da Casa com poder propositivo. Há também, significativa participação da Sociedade Civil por meio das SUG. Enquanto Câmara Revisora, é notável que esta emite pareceres de frequência significativa de pautas de origem dos Deputados. Sendo assim, se encontra uma comissão com foco em se institucionalizar e atuar no âmbito de Direitos Humanos e Legislação Participativa.

Sobre os pareceres em geral, a comissão em primeiro ponto tende a aprovar em maior taxa as pautas que passam por ela, seguidos das alterações com emendas e substitutivos. Retira as SUGs da equação, por haver tramite diferente, esse papel se inverte: a comissão tem como foco alterar a maior parte das matérias que tramitam no seu interior, o que é um traço já apresentado por Freitas (2016) ao tratar da atuação do legislativo nos projetos iniciados pelo Executivo.

Quando retratado as proposições que chegam à comissão, observa-se que há ampla gama de partidos propositores. Porém, é visto que quase metade das proposições pertencem ao PT, PMDB e PSDB. Vendo a indicação dos relatórios por partido propositor, observasse que quase metade de todas as propostas passaram por alteração no interior da comissão, também é notável que a taxa de aprovados apresenta significativa proporção, sendo estes os resultados mais frequentes.

Visto as proposições pelo prisma da coalizão, é notável que há grande importância para esta função, os governos Lula I e II, mas cai nos governos Dilma I e II e obtém a sua menor participação no governo Temer. Sobre os relatórios feitos nas proposições da coalizão, é visto que a maioria tem por parecer emendas e substitutivos, o que demonstra que propor e ser da base não dá a segurança de ter o conteúdo das suas matérias assegurado na integra.

Sobre o cargo de relator na comissão, o primeiro ponto a destacar é a predominância do PT, com quase metade das relatorias feitas na comissão, observa-se o controle do partido na comissão. Visto que, segundo Souza e Silva (2019), este possui a presidência em 66,7\% dos casos, assim como participação no plenário da $\mathrm{CDH}$ é notável a capacidade de controle da agenda do partido nessa comissão. O que aponta para a mesma direção da teoria partidária, pois o partido, controla presidência, relatorias e possui contingente para aprovar a pauta devido a presença da coalizão na comissão, fortalecendo assim a imagem do partido perante o seu eleitorado. 
Referente a indicação do relatório por partido do relator, é visto que a maioria das indicações são pela aprovação seguidos de alterações, o que contrasta por partido propositor. Porém, vale ressaltar que nesses dados estão presentes as SUG (que aumentam a porcentagem de Emendas/Substitutivos) pois se conta todos os projetos relatados, enquanto na tabela 10 encontra-se somente os Projetos de Lei feitos por partido. Assim, ainda se mantém a imagem do poder positivo da comissão de alterar e modificar as pautas no seu interior.

Sobre a participação da coalizão nas relatorias, se vê crescente participação nos governo Lula e Dilma; porém, esta taxa tem declínio forte no governo Temer, o que pode ser resultado do controle feito na comissão pelo PT, haja vista que nos anos de 2016-2018 a presidência se encontrava nas mãos desse partido. E como a atribuição de escolher o relator é da presidência da comissão, se espera essa baixa frequência de relatores por este governo.

Tendo em vista, a indicação dos relatores pela base governista, a maior parte das relatorias são pela aprovação, seguido da alteração. Assim, é notável que há traços de diminuição de incertezas devido a significativa taxa de alteração e que o governo tende a aprovar mais as matérias.

Retratado os resultados por legislatura, é visível a tendência da comissão de aprovar as pautas, seguida das alterações, nota-se também que há um crescimento contínuo da rejeição na comissão.

Dessa forma, assim se configura a CDH. Uma comissão que apresenta alta institucionalização, com crescente número de reuniões, sendo a maioria informacional. Tendo respaldo no que trata o poder positivo enquanto aprovação e alteração. Tem forte presença e controle de um partido (PT) com presidência e relatoria -, o que reforça a capacidade explicativa do modelo partidário. Todavia, essa preponderância do PT não significa um controle absoluto: nota-se o alto número de partidos com membros indicados para relatorias. A coalizão tem atuação nítida no trabalho da comissão, de início nas proposições que no decorrer diminui a incidência e nas relatorias, onde a participação aumenta.

\section{BIBLIOGRAFIA}

ALMEIDA, A. Boletim de Análise Político Institucional. n.7, 2015.

ALMEIDA, A. Do plenário às comissões: mudança institucional na Câmara dos Deputados. In: PERLIN, G, SANTOS, M.L. Presidencialismo de coalizão em movimento. Brasília: Edições Câmara, 2019

AMARAL, Ana Regina Villar Peres. O Parlamento Brasileiro: Processo, Produção e Organização Legislativa - O Papel das Comissões em Perspectiva Comparada. In: Nicolau, Jairo e BRAGA, Ricardo de João. Para além das urnas: reflexões sobre a câmara dos deputados. Brasília: Centro de documentação e Informação-Edições Câmara, p. 149-177 
ARAÚJO, P. M. O bicameralismo no Brasil: argumentos sobre a importância do Senado na análise do processo decisório federal. Política \& Sociedade, v.11, n.21, 2012

ARAÚJO, P. M. A Câmara Alta no presidencialismo de coalizão: o desempenho legislativo do Senado entre 1989 e 2000 In: LEMOS, L. B. (Org.). O Senado Federal brasileiro no pós-constituinte. Brasília: Senado Federal; Unilegis, 2008

BRASIL. SENADO FEDERAL. Regimento Interno do Senado Federal. Disponível em: https://www25.senado.leg.br/documents/12427/45868/RISF+2018+Volume+1.pdf/cd5769c8-46c54c8a-9af7-99be436b89c4. Acesso em: 10/03/2020

FREITAS, Andréia. O presidencialismo da coalizão. Rio de Janeiro: Fundação Konrad Adenauer, 2016 (capítulo 3, p. 60-84)

FREITAS, A, VASQUEZ. Estudos Legislativos no Brasil. Cadernos Adenauer, vol XVIII, n. 2, 2017

NASCIMENTO, E. O. O sistema de comissões brasileiro: elementos para uma agenda de pesquisa. Revista de ciência política brasileira, vol. 21, n. 2, p. 61-72, jul./dez. 2012.

SANTOS, F. Partidos e Comissões no Presidencialismo de Coalizão. DADOS vol. 45 n² 2, 2002

SANTOS, F. e ALMEIDA, A. Fundamentos Informacionais do Presidencialismo de Coalizão. Curitiba: Appris, 2011

LEMOS, L. B.; RANINCHESKI, S. Carreiras políticas no Senado brasileiro: um estudo das composições do Plenário e da Comissão de Justiça e Cidadania na década de 1990. In: LEMOS, L. B. (Org.). O Senado Federal brasileiro no pós-constituinte. Brasília: Senado Federal; Unilegis, 2008

LIMONGI, Fernando e FIGUEIREDO, Argelina. Bases institucionais do presidencialismo de coalizão. Lua nova, n. 44, 1998 p. 81-106

RICCI, P. A produção legislativa de iniciativa parlamentar no Congresso: diferenças e similaridades entre a Câmara dos Deputados e o Senado Federal In: LEMOS, L. B. (Org.). O Senado Federal brasileiro no pós-constituinte. Brasília: Senado Federal; Unilegis, 2008

ROCHA, M. M.; BARBOSA, C. F. Regras Incentivos e Comportamento: as comissões parlamentares nos países do cone sul. Revista de Sociologia e Política, n.16-complementar, 2008

RUBIATTI, B. C. Sistema de resolução de conflitos e o papel do Senado como câmara revisora no Bicameralismo Brasileiro, Revista Brasileira de Ciência Política, n.23, 2017, p. 35-74

RUBIATTI, B. C.. Os estudos legislativos no Brasil: agendas de pesquisa. Caos - Revista Eletrônica de Ciências Sociais, João Pessoa, n. 23, p 12-35, jul./dez. 2019. Disponível em: https://periodicos. ufpb.br/ojs2/index.php/caos/index. 
SOUZA E SILVA, J. N. A. A comissão de direitos humanos e legislação participativa (CDH) no senado brasileiro: um estudo sobre sua composição (2005-2018). Caos - Revista Eletrônica de Ciências Sociais, João Pessoa, n. 23, p. 79 -112, jul./dez. 2019. Disponível em: https://periodicos.ufpb.br/ojs2/index.php/caos/index 